Article

\title{
Hydrogen Interaction with Deep Surface Modified Zr-1Nb Alloy by High Intensity Ti Ion Implantation
}

\author{
Egor B. Kashkarov ${ }^{1, *(\mathbb{D})}$, Alexander I. Ryabchikov ${ }^{2}$, Alexander V. Kurochkin ${ }^{1}$, \\ Maxim S. Syrtanov ${ }^{1}$, Alexey E. Shevelev ${ }^{2} \mathbb{D}$, Aleksei Obrosov ${ }^{3}\left(\mathbb{D}\right.$ and Sabine Weiß ${ }^{3}$ (D) \\ 1 School of Nuclear Science and Engineering, National Research Tomsk Polytechnic University, \\ Tomsk 634050, Russia; avkurochkin93@mail.ru (A.V.K.); maxim-syrtanov@mail.ru (M.S.S.) \\ 2 Research School of High-Energy Physics, National Research Tomsk Polytechnic University, \\ Tomsk 634050, Russia; ralex@tpu.ru (A.I.R.); shevelevae@tpu.ru (A.E.S.) \\ 3 Department of Physical Metallurgy and Materials Technology, Brandenburg Technical University, \\ 03046 Cottbus, Germany; aleksei.obrosov@b-tu.de (A.O.); sabine.weiss@b-tu.de (S.W.) \\ * Correspondence: egor_kashkarov@mail.ru; Tel.: +7-(952)-802-0688
}

Received: 26 November 2018; Accepted: 17 December 2018; Published: 19 December 2018

check for updates

\begin{abstract}
A deep surface modified TiZr layer was fabricated by high-intensity low-energy titanium ion implantation into zirconium alloy $\mathrm{Zr}-1 \mathrm{Nb}$. Gas-phase hydrogenation was performed to evaluate protective properties of the modified layer against hydrogen permeation into $\mathrm{Zr}-1 \mathrm{Nb}$ alloy. The effects of ion implantation and hydrogen on microstructure, phase composition and elemental distribution of TiZr layer were analyzed by scanning electron microscopy, X-ray diffraction, and glow-discharge optical emission spectroscopy, respectively. It was revealed that TiZr layer ( $10 \mu \mathrm{m}$ thickness $)$ is represented by $\alpha^{\prime}+\alpha(\mathrm{TiZr})$ lamellar microstructure with gradient distribution of Ti through the layer depth. It was shown that the formation of TiZr layer provides significant reduction of hydrogen uptake by zirconium alloy at 400 and $500{ }^{\circ} \mathrm{C}$. Hydrogenation of the modified layer leads to refinement of lamellar plates and formation of more homogenous microstructure. Hydrogen desorption from Ti-implanted $\mathrm{Zr}-1 \mathrm{Nb}$ alloy was analyzed by thermal desorption spectroscopy. Hydrogen interaction with the surface modified TiZr layer, as well as its resistance properties, are discussed.
\end{abstract}

Keywords: zirconium alloy; titanium; low energy ion implantation; hydrogen; sorption; microstructure; morphology; martensitic phase

\section{Introduction}

Zirconium-based alloys are widely used as the main structural material in nuclear reactors due to low thermal neutron cross-section, high melting point, high corrosion resistance in water at $280-350{ }^{\circ} \mathrm{C}$ and acceptable mechanical properties. The operation experience of nuclear reactors showed that zirconium alloys are subjected to corrosion and hydrogen embrittlement [1,2]. Hydrogen is generated during water radiolysis and corrosion reaction between zirconium and water under reactor operation. Hydrogenation of $\mathrm{Zr}$ alloys to local or total critical concentrations leads to embrittlement of fuel claddings caused by brittle hydrides precipitations [3,4]. The rate of hydrogen uptake observed during corrosion is affected not only by the chemical composition of zirconium alloys but also by their microstructure and surface oxide morphology $[5,6]$. It has been shown that un-oxidized particles precipitated at the oxide/metal interface may act as preferential paths for hydrogen permeation to the metal matrix $[7,8]$. The delayed hydride cracking (DHC) mechanism has been proposed to describe crack propagation initiated at the outer cladding surfaces $[9,10]$. It has been shown that cracks formed in the oxide layer result in hydrogen enrichment close to the metal surface [11]. 
Higher fuel consumption and power up-rating for reactor operation require the development of the advanced zirconium alloys exhibiting better corrosion resistance and lower hydrogen uptake [12,13]. An alternative way to enhance corrosion resistance and reduce hydrogenation of zirconium alloys is coating deposition or surface modification [14]. Currently, there are various deposition technologies and coatings providing better resistance of zirconium alloys during steam corrosion and accident conditions, such as $\mathrm{Cr}[15,16]$, TiN, and TiN/TiAlN [17-19], micro arc oxidation coatings [20], CrN and $\mathrm{AlCrN}$ [21], and others. From the point of coating development, a requirement is to deposit protective coatings that retain their adhesive properties under normal reactor and accident conditions and demonstrate wear resistance due to the possibility of damage during claddings assembly. Surface modification by charged particle beams is perspective due to the absence of problems with adhesion of the modified layer. It has been shown that surface layers modified by electron beam demonstrate higher mechanical properties and hydrogen resistance as compared with untreated zirconium alloys [22]. Significant reduction of hydrogenation of $\mathrm{Zr}-1 \mathrm{Nb}$ alloy has been achieved by plasma-immersion Ti ion implantation due to the formation of $\mathrm{TiO}_{2}$ and $\mathrm{ZrO}_{2}$ surface oxides and trapping of hydrogen in the ion-modified layer $[23,24]$. It was also found that the corrosion resistance increased after Ti implantation and is dependent on the thickness of the modified layer $[25,26]$. However, traditional ion implantation techniques are generally limited by the projected range of ions in the target material, which usually does not exceed a micrometer. Therefore, the protective properties of such layers are degraded quickly. It has been shown in our previous research that realization of high-intensity repetitively pulsed ion implantation from filtered vacuum arc plasma makes it possible to form deep modified layers (several microns) with a high concentration of dopant [27]. The improved mechanical and tribological properties of Ti-implanted zirconium alloy were also demonstrated. However, the effect of a deep TiZr surface layer on microstructure and hydrogen resistance properties of $\mathrm{Zr}$ alloys are still unstudied. Moreover, the effect of hydrogen on Ti-Zr systems, as well as the mechanism of phase formation and microstructure evolution under high-intensity ion implantation, is also still unclear. At the same time, Ti-Zr systems are of the great interest for biomedical fields and the aerospace industry due to their better biocompatibility than of pure Ti [28], higher mechanical properties [29], and shape memory effect as reported by Li et al. [30]. The influence of hydrogen on the structure of Ti-Zr surface layer is also important in the view of chemical treatments by $\mathrm{H}$-contained solutions to enhance the performance of TiZr [31]. Therefore, this research aimed to investigate the microstructure and phase formation in the deep modified Ti-Zr surface layer as well as its hydrogen resistance properties.

\section{Materials and Methods}

\subsection{Sample Preparation and Implantation Procedure}

Rectangular samples with dimensions of $20 \times 20 \times 2 \mathrm{~mm}$ were cut from a cold-rolled $\mathrm{Zr}-1 \mathrm{Nb}$ sheet (composition: $0.9-1.1 \mathrm{Nb}, 0.05 \mathrm{O}, 0.015 \mathrm{Fe}, 0.02 \mathrm{C}$, Zr balanced) and used as target material. The samples were ground and polished to eliminate surface defects and smooth the surface. Then the samples were ultrasonically cleaned in acetone for $20 \mathrm{~min}$. According to the results of contact profilometry, the average surface roughness of the samples was $R_{a}=0.070 \pm 0.005 \mu \mathrm{m}$. To relieve internal stresses, the samples were annealed in a vacuum at $580^{\circ} \mathrm{C}$ for $3 \mathrm{~h}$.

High-intensity low-energy ion implantation of titanium was carried out using experimental setup schematically illustrated in Reference [27]. For the generation of DC flow of metal plasma, a water-cooled vacuum arc evaporator was used, and the discharge current was equal to $130 \mathrm{~A}$. The cathode of the evaporator was made of VT1-0 alloy (99.95\% purity). A partially hemispherical grid electrode and a cylindrical drift section, made of stainless steel, were electrically attached and mounted on the axis of vacuum arc evaporator at the distance of $40 \mathrm{~cm}$ from the cathode working surface. The curvature radius of the grid electrode was $7.5 \mathrm{~cm}$ at the mesh size of $1.4 \times 1.4 \mathrm{~mm}$. The length of the cylindrical section was slightly longer than the focusing distance predefined by the grid curvature radius and equal to approx. $10 \mathrm{~cm}$. For purification of vacuum arc plasma flow 
from the macroparticles, a metal disc mounted on the grid electrode preventing the straight flight of macroparticles to the irradiated area of the sample was used [32]. The residual gas pressure in the working chamber was equal to $10^{-3} \mathrm{~Pa}$ and slightly improved during the processing due to gas absorption (gettering) by titanium coating deposited on the chamber walls [33].

The formation of the ion beams in the presented approach is provided by the application of negatively pulsed bias to the system immersed in the plasma. A high voltage generator provided the amplitude of bias voltage of $1.5 \mathrm{kV}$, a pulse duration of $5 \mu \mathrm{s}$ and pulse repetition rate of $10^{5}$ pulses per second (p.p.s) was used. After the system biasing, a space charge separation layer usually referenced as sheath formed in front of the grid electrode and the process of ion extraction and acceleration occurred [34]. High ion current densities of vacuum arc plasma (equal to $5 \mathrm{~mA} / \mathrm{cm}^{2}$ at the reference distance) provided the total extracted ion current up to $0.5 \mathrm{~A}$ with this geometry and voltage amplitude. After passing through the grid, ions entered the initially equipotential drift space, however, without the conditions of their space charge neutralization, they induced a significant potential drop due to their high perveance and, therefore, cannot propagate. Space charge neutralization in this system was realized due to the pulsed nature of the biasing voltage. During the off-pulse cycle vacuum, arc plasma, which has very high direction velocity of $2 \times 10^{4} \mathrm{~m} / \mathrm{s}$ streams into drift space and, in its turn, a very high degree of beam space charge neutralization, was achieved [35]. The beam focusing is almost defined by the ballistic trajectory to a very high current density of $100 \mathrm{~mA} / \mathrm{cm}^{2}$. The ion current measurements were performed with Rogowski coil. More data concerning the processes of beam formation and its dynamics can be found in the Reference [36].

The implantation time was $60 \mathrm{~min}$ with the additional preheating for $15 \mathrm{~min}$. The temperature of the irradiated target was measured by an isolated thermocouple mounted on backside of the sample and reached $700{ }^{\circ} \mathrm{C}$. The dose of ion irradiation was estimated according to the formula [37]:

$$
\mathrm{D}=6.25 \times 10^{18} \times \mathrm{j} \times \mathrm{t} \times \mathrm{f} \times \tau / \mathrm{Z}
$$

where $\mathrm{j}$-ion current density, $\mathrm{t}$ - treatment time; $\mathrm{f}$ - pulse repetition rate; $\tau$ —-pulse duration; $\mathrm{Z}$-mean charge state of titanium ions. The calculated dose was $\mathrm{D}=4.5 \times 10^{20} \mathrm{ion} / \mathrm{cm}^{2}$.

\subsection{Hydrogenation}

Hydrogenation was carried out using the automated complex Gas Reaction Controller LPB (Advanced Materials Corporation, Pittsburgh, PA, USA). Hydrogen was produced by pyrolysis method on hydrogen generator HyGen 200 (Wallingford, CT, USA). The purity of the generated hydrogen was $99.9995 \%$. The hydrogenation was carried out at temperatures of $400{ }^{\circ} \mathrm{C}$ and $500{ }^{\circ} \mathrm{C}$. The heating rate was $6^{\circ} \mathrm{C} / \mathrm{min}$. After hydrogenation, the samples were cooled in a vacuum. The cooling rate was $\sim 1.5-2{ }^{\circ} \mathrm{C} / \mathrm{min}$. The values of pressure and temperature in the reaction chamber were recorded every three seconds. Absolute hydrogen concentrations in the samples were measured by the hot extraction method using hydrogen analyzer RHEN602 (LECO, Saint Joseph, MO, USA) [38].

\subsection{Characterization}

Surface morphology and elemental composition were investigated by scanning electron microscopy (SEM) using TESCAN Mira II (Brno, Czech Republic) equipped with energy-dispersive X-ray (EDX) spectroscopy attachment (Oxford Analysis, Wiesbaden, Germany). For cross-section SEM analysis after hydrogenation, the polished samples were chemically etched with a solution of $\mathrm{HNO}_{3}, \mathrm{HF}$, and $\mathrm{H}_{2} \mathrm{O}$ (45.5 and 50 vol.\%, respectively). Depth distribution of elements was analyzed by glow-discharge optical emission spectroscopy (GDOES) using GD Profiler 2 (Horiba, Japan).

Crystalline structure and phase composition were analyzed by $\mathrm{X}$-ray diffraction ( $\mathrm{Cu} K_{\alpha}$ radiation) using XRD 7000S diffractometer (Shimadzu, Japan) equipped with high-speed wide-range 1280 channels detector OneSight (Shimadzu, Japan). The diffraction data were analyzed using Sleve+ program. As a 
reference for the patterns of $\alpha-\mathrm{Zr}, \mathrm{Zr}_{0.7} \mathrm{Ti}_{0.3}, \mathrm{Zr}_{0.5} \mathrm{Ti}_{0.5}, \gamma-\mathrm{ZrH}$ and $\delta-\mathrm{ZrH}$ the ICDD PDF-4+ database: \#04-004-8479, \#01-072-3354,\#04-003-5040, \#03-0656223 and \#04-002-2839 was used, respectively.

Thermal desorption analysis (TDS) was carried out using Stanford Research Systems' quadrupole mass spectrometer RGA100, which is a part of Gas Reaction Controller complex. The samples were heated up to $960{ }^{\circ} \mathrm{C}$ with the linear heating rate of $3{ }^{\circ} \mathrm{C} / \mathrm{min}$.

\section{Results and Discussion}

\subsection{Structure and Composition of Ti-Implanted Zr-1Nb Alloy}

Figure 1a shows the cross-section SEM image of the $\mathrm{Zr}-1 \mathrm{Nb}$ alloy after high-intensity ion implantation demonstrating the microstructure of the Ti-implanted layer. The thickness of this layer was $9.1 \pm 1.4 \mu \mathrm{m}$. The implanted layer has a lamellar microstructure with disoriented coarse lamellar plates of the $\alpha^{\prime}$ martensitic phase and $\alpha$ (ZrTi) phase intertwined with each other (Figure 1a inset). The distribution of elements along the implanted layer was analyzed by EDX (Figure 1b). Titanium has gradient distribution through the implanted layer up to $\sim 10 \mu \mathrm{m}$ in depth. The highest concentration of titanium in the surface layer was 55 at.\%.
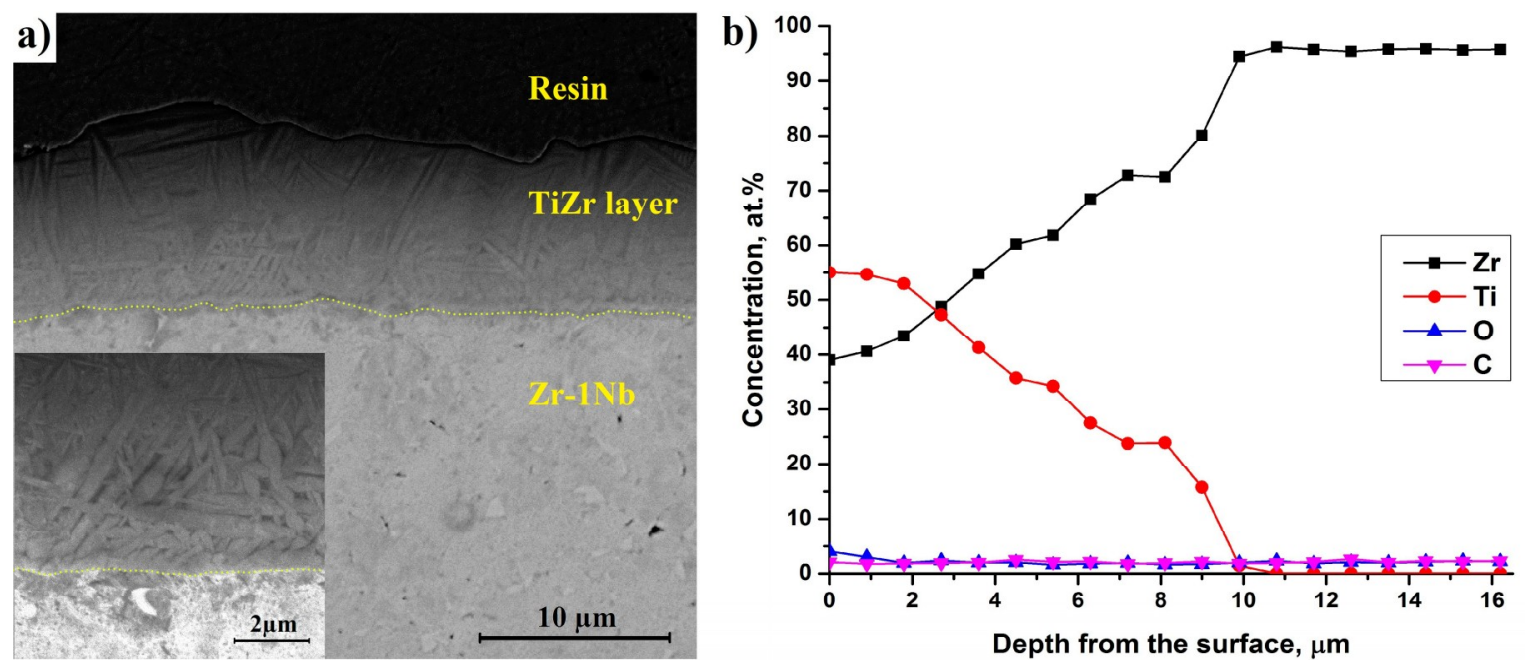

Figure 1. Cross-section scanning electron microscopy (SEM) image of (a) Ti-implanted Zr-1Nb and (b) depth distribution of elements measured by EDX.

Figure 2 shows $\mathrm{X}$-ray diffraction analysis of Ti-implanted and as-received $\mathrm{Zr}-1 \mathrm{Nb}$ alloy. It can be observed that the as-received alloy is characterized by hexagonal close-packed (hcp) crystal structure with the lattice parameters $\mathrm{a}=3.2364 \AA$ and $\mathrm{c}=5.1451 \AA$. The crystal structure of the surface layer significantly changed after high-intensity Ti ion implantation. In addition to the $\alpha$ phase of zirconium, intermetallic phases based on $\mathrm{Zr}$-Ti compounds were formed. The Zr-Ti phases also had hcp $\alpha\left(\alpha^{\prime}\right)$ structure of different compositions: $\mathrm{Zr}_{0.5} \mathrm{Ti}_{0.5}$ (54 vol.\%) and $\mathrm{Zr}_{0.7} \mathrm{Ti}_{0.3}$ (43 vol.\%). The calculated values of lattice parameters of the phases and microstrains are presented in Table 1. It can be observed that the fraction of the residual $\alpha$ phase in the investigated volume is $4 \%$ after Ti ion implantation. A decrease in the lattice parameter a and an increase in the parameter $\mathrm{c}$ of $\alpha$ phase are observed. Therefore, the lattice distortion (increase in the $\mathrm{c} / \mathrm{a}$ ratio) of the $\alpha$ zirconium phase occurs, which is most likely related to the formation of crystal lattice defects caused by incorporation of Ti atoms into $\mathrm{Zr}$ lattice. Higher microstrains after implantation also indicate the crystal lattice deformation. 


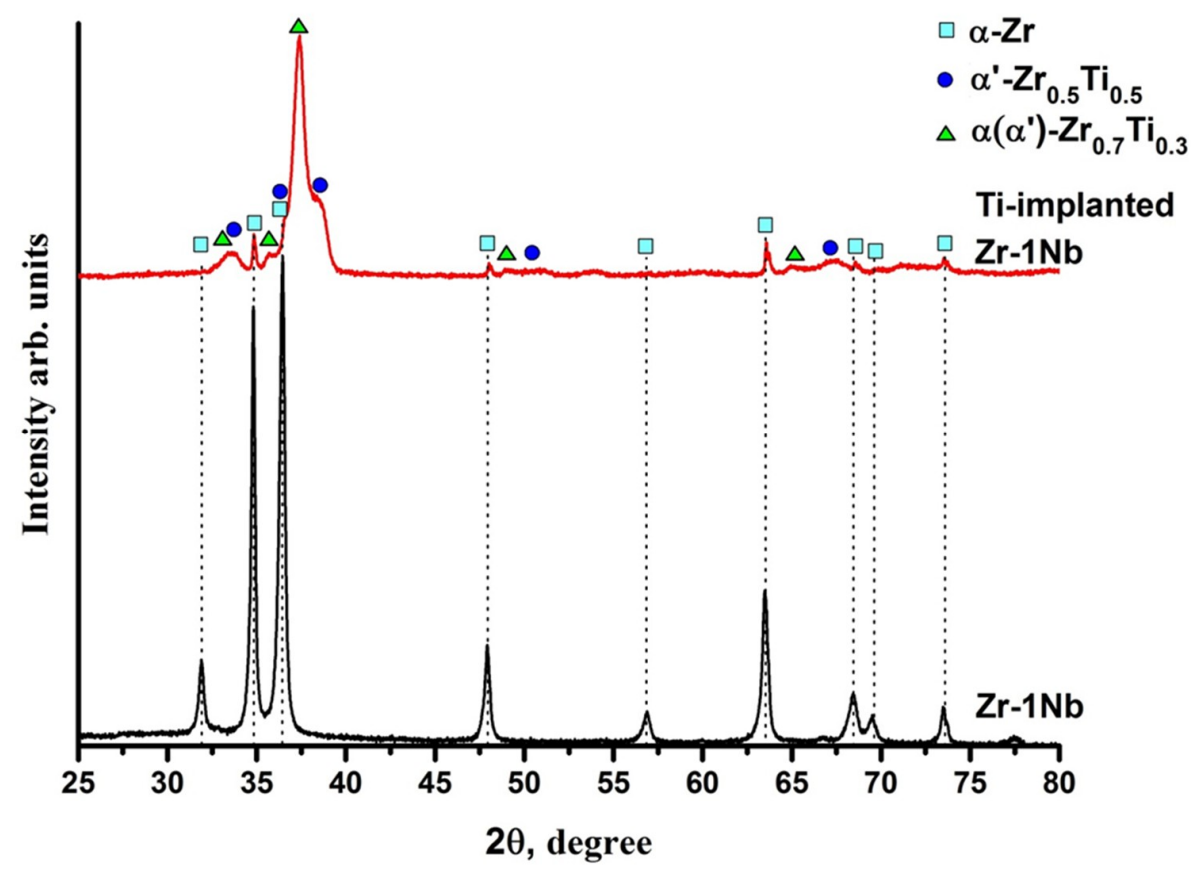

Figure 2. X-ray diffraction (XRD) patterns of (a) as-received and (b) Ti-implanted Zr-1Nb alloy.

The formation of $\mathrm{Zr}$-Ti phases after ion implantation is attributed to a substitutional solid solution of Ti into Zr lattice [39]. The results are similar to the research of Zhou et al. [40] who showed that the binary Zr-Ti cast alloys with Ti concentration of 10 to 90 at.\% are composed of $\alpha$ phase. However, the present study shows the formation of martensitic $\alpha^{\prime}$ phase in the surface modified layer confirmed by electron microscopy analysis. Such martensitic $\alpha^{\prime}$ phase is typical for the quenched $\mathrm{Ti}_{50} \mathrm{Zr}_{50}$ alloy as by Li et al. demonstrated [30]. Therefore, the presence of a martensitic phase indicates thermal induced phase transformations during ion implantation occurred. It has been reported that the transus temperature of $\beta$ phase $\left(\mathrm{T}_{\beta}\right)$ in Ti-Zr system with a high content of $\mathrm{Zr}$ is significantly lower than that in pure Ti or $\mathrm{Zr}$ [41]. The $\mathrm{T}_{\beta}$ value for $\mathrm{Ti}_{0.5} \mathrm{Zr}_{0.5}$ is $600-620{ }^{\circ} \mathrm{C}$ according to References [30,41]. Considering that the implantation temperature was $\sim 700{ }^{\circ} \mathrm{C}$ it is supposed that the formation of TiZr layer during implantation takes place in the $\beta$ phase. Therefore, this layer undergoes $\beta \rightarrow \alpha$ phase transformation during cooling after ion implantation. Cooling of the sample in a vacuum chamber occurred mainly due to radiative transfer; therefore, the cooling rate is proportional to $\sigma \mathrm{T}^{4}$ in accordance with Boltzmann law, which favors the processes of martensitic transformations similar to quenching. The martensitic phases in Ti alloys are greatly dependent on the value of e/a in accordance with the valence electron theory. Lin et al. showed that the martensitic phase in Ti alloys with the value e/a below 4.07 should be $\alpha^{\prime}$ phase [42]. The e/a value for Ti-Zr system is four. Thus, the formation of $\alpha^{\prime}$ martensitic phase in the implanted layer is in agreement with this theory and other reported data on Ti-Zr systems.

Table 1. The results of X-ray diffraction (XRD) analysis.

\begin{tabular}{|c|c|c|c|c|c|}
\hline Sample & Phase & Phase Content, $\%$ & Lattice Parameters, Å & $\mathrm{c} / \mathbf{a}$ & Microstrain $\Delta d / d, 10^{-3}$ \\
\hline $\mathrm{Zr}-1 \mathrm{Nb}$ & $\alpha-Z r$ (hcp) & 100 & $\begin{array}{l}\mathrm{a}=3.2364 \\
\mathrm{c}=5.1451\end{array}$ & 1.590 & 1.5 \\
\hline \multirow{3}{*}{ Ti-implanted Zr-1Nb } & $\alpha-Z r$ (hcp) & 4 & $\begin{array}{l}\mathrm{a}=3.2325 \\
\mathrm{c}=5.1507\end{array}$ & 1.594 & 2.2 \\
\hline & $\mathrm{Zr}_{0.5} \mathrm{Ti}_{0.5}(\mathrm{hcp})$ & 54 & $\begin{array}{l}\mathrm{a}=3.0886 \\
\mathrm{c}=4.8438\end{array}$ & 1.568 & 4.3 \\
\hline & $\mathrm{Zr}_{0.7} \mathrm{Ti}_{0.3}(\mathrm{hcp})$ & 43 & $\begin{array}{l}a=3.1613 \\
c=5.0229\end{array}$ & 1.589 & 4.8 \\
\hline
\end{tabular}




\subsection{Hydrogen Sorption Behavior}

Hydrogenation was carried out at a constant temperature of 400 and $500{ }^{\circ} \mathrm{C}$. Figure 3 shows the hydrogen sorption curves by the as-received and Ti-implanted alloy samples for comparison. The slope of the curves characterizes the intensity of hydrogen absorption by the samples. It can be observed that the formation of Ti-implanted layer significantly reduces hydrogenation of $\mathrm{Zr}-1 \mathrm{Nb}$ alloy. At the temperature of $400{ }^{\circ} \mathrm{C}$, the as-received sample was hydrogenated to $530 \mathrm{ppm}$ for $4.7 \mathrm{~h}$, while the Ti-implanted sample for $26.7 \mathrm{~h}(\mathrm{CH}=400 \mathrm{ppm})$. The hydrogenation increased with temperature both for the as-received alloy and the alloy after ion implantation. The Ti-implanted samples were hydrogenated to $500 \mathrm{ppm}$ for $3.6 \mathrm{~h}$ at $500{ }^{\circ} \mathrm{C}$, while the as-received alloy for $47 \mathrm{~min}(\mathrm{CH}=650 \mathrm{ppm})$.
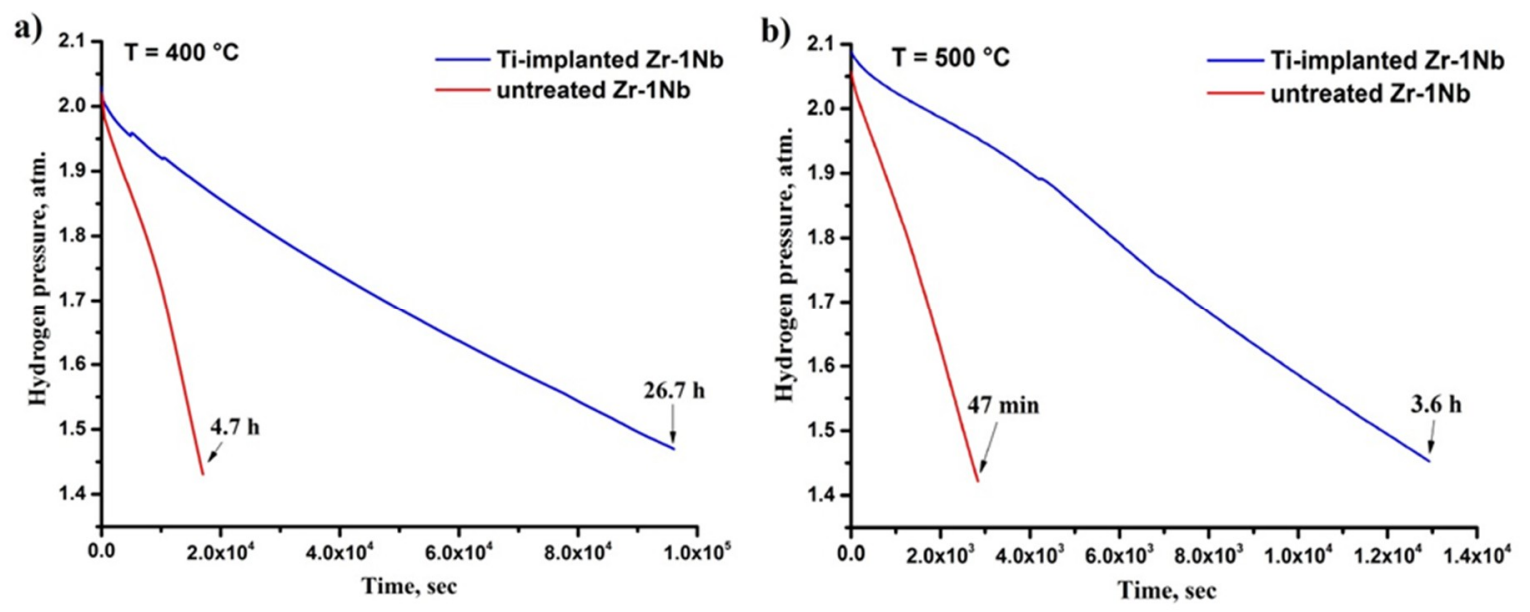

Figure 3. Hydrogen pick-up curves at (a) $400{ }^{\circ} \mathrm{C}$ and (b) $500{ }^{\circ} \mathrm{C}$.

For quantitative analysis of hydrogenation, the hydrogen absorption rate was calculated using the following equation [24]:

$$
\mathrm{Q}=\frac{\mathrm{V}}{\mathrm{t} \times \mathrm{S}} \frac{\mathrm{P}_{0}-\mathrm{P}}{\mathrm{P}}
$$

where $\mathrm{V}$-volume of the chamber $\left(\mathrm{cm}^{3}\right), \mathrm{t}$-hydrogenation time, $\mathrm{S}$ - effective surface area of the samples $\left(\mathrm{cm}^{2}\right), \mathrm{P}_{0}$ and $\mathrm{P}$ - starting and final pressure in the chamber (atm.), respectively.

The calculated values of the hydrogen absorption rate are presented in Table 2. The rate of hydrogen absorption by $\mathrm{Zr}-1 \mathrm{Nb}$ alloy was decreased by 6.3 times at $400^{\circ} \mathrm{C}$ and 4.7 times at $500^{\circ} \mathrm{C}$ due to the formation of Ti modified surface layer. It indicates the protective barrier properties of Ti-implanted layer against hydrogen permeation in the indicated temperature range.

Table 2. Hydrogen absorption rate.

\begin{tabular}{cccc}
\hline \multirow{2}{*}{ Temperature, ${ }^{\circ} \mathbf{C}$} & \multicolumn{2}{c}{ Hydrogen Absorption Rate $\mathbf{Q}, \times \mathbf{1 0}-\mathbf{6} \mathbf{c m}^{\mathbf{3}} \mathbf{H}_{\mathbf{2}} / \mathbf{( \mathbf { s } \cdot \mathbf { c m } ^ { \mathbf { 2 } } )}$} & \multirow{2}{*}{ Reduction Ratio } \\
\cline { 2 - 3 } & $\mathbf{Z r - 1 N b}$ Alloy & Ti-implanted $\mathbf{Z r - 1 N b}$ & \\
\hline 400 & 4.4 & 0.7 & 6.3 \\
500 & 28.7 & 6.1 & 4.7 \\
\hline
\end{tabular}

\subsection{Structure and Elemental Distribution in Hydrogenated Samples}

The depth distribution of elements in a hydrogenated Ti-implanted sample is shown in Figure 4. The distribution of $\mathrm{Ti}$ and $\mathrm{Zr}$ elements through the depth is similar to those measured by EDX. Hydrogen in the modified layer has non-uniform distribution: The $\mathrm{H}$ concentration is the highest in the surface layer up to $1.5 \mu \mathrm{m}$ in depth and then decreases with increasing analyzing depth. The Ti-contained layer could be divided into three sections. Due to a high concentration of hydrogen in the surface layer (I section), it would be expected that this layer consists of titanium-zirconium 
hydrides. The next section demonstrates the mixed $\mathrm{Zr}$-Ti layer composed of two $\alpha^{\prime}+\alpha(\mathrm{TiZr})$ phase with dissolved hydrogen. The third section is attributed to the intermediate layer mainly consisting of $\alpha$ zirconium phase distorted by titanium and hydrogen incorporation.

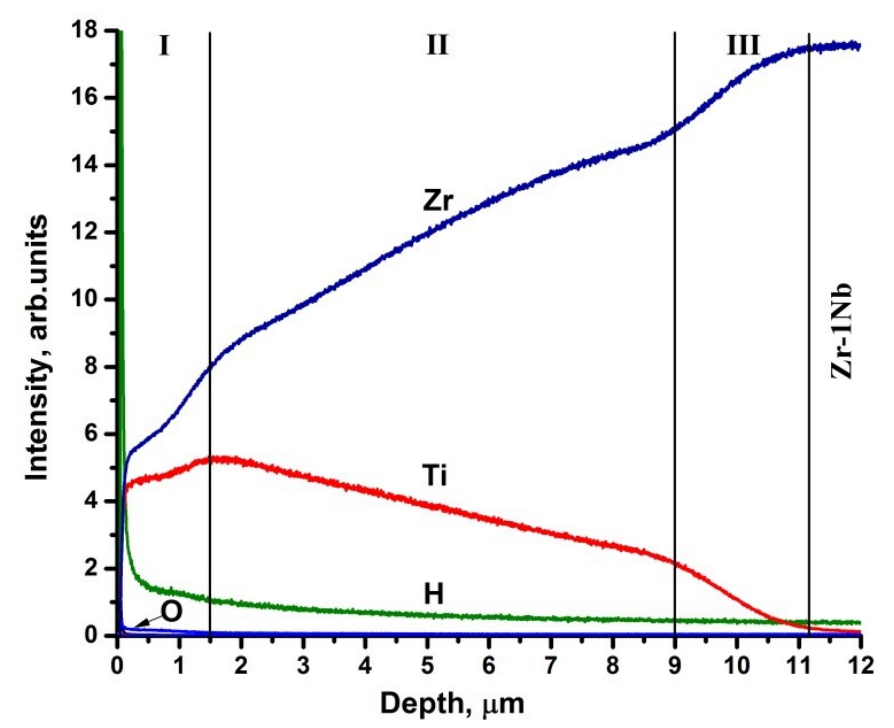

Figure 4. Glow-discharge optical emission spectroscopy (GDOES) profiles of elements in Ti-implanted alloy hydrogenated at $500{ }^{\circ} \mathrm{C}$.

The crystalline structure of the hydrogenated samples is shown in Figure 5. The calculated phase content and lattice parameters are presented in Table 3. Zirconium hydrides with the cubic crystal structure $\left(\delta-\mathrm{ZrH}_{1.66}\right)$ and tetragonal $\gamma-\mathrm{ZrH}$ are detected in hydrogenated $\mathrm{Zr}-1 \mathrm{Nb}$ alloy. The content of $\delta$ hydrides in the analyzed depth is $53 \mathrm{vol} \%$. The $\alpha-\mathrm{Zr}$ phase is also presented in the structure. However, the ratio of lattice parameters c/a of the $\alpha$ phase increased from 1.590 (as-received state) to 1.596 due to distortion of the crystal lattice by hydrogen dissolution. Inverse relationship (decrease in c/a ratio) is observed in the Ti-implanted samples. The latter may indicate that the presence of $\mathrm{Ti}$ in $\mathrm{Zr}$ lattice affects the position of hydrogen in the $\alpha$ phase. At the same time, a decrease in the intensity of $\alpha^{\prime}-Z_{0.5} \mathrm{Ti}_{0.5}$ reflex at the position of $2 \theta=38.2^{\circ}$ and an increase of the reflex at $2 \theta=33.5^{\circ}$ are observed (Figure 5b). The calculated phase composition indicates a decrease in the content of martensitic $\alpha^{\prime}-\mathrm{Zr}_{0.5} \mathrm{Ti}_{0.5}$ phase relative to the $\alpha\left(\alpha^{\prime}\right)-\mathrm{Zr}_{0.7} \mathrm{Ti}_{0.3}$ phase (Table 3).
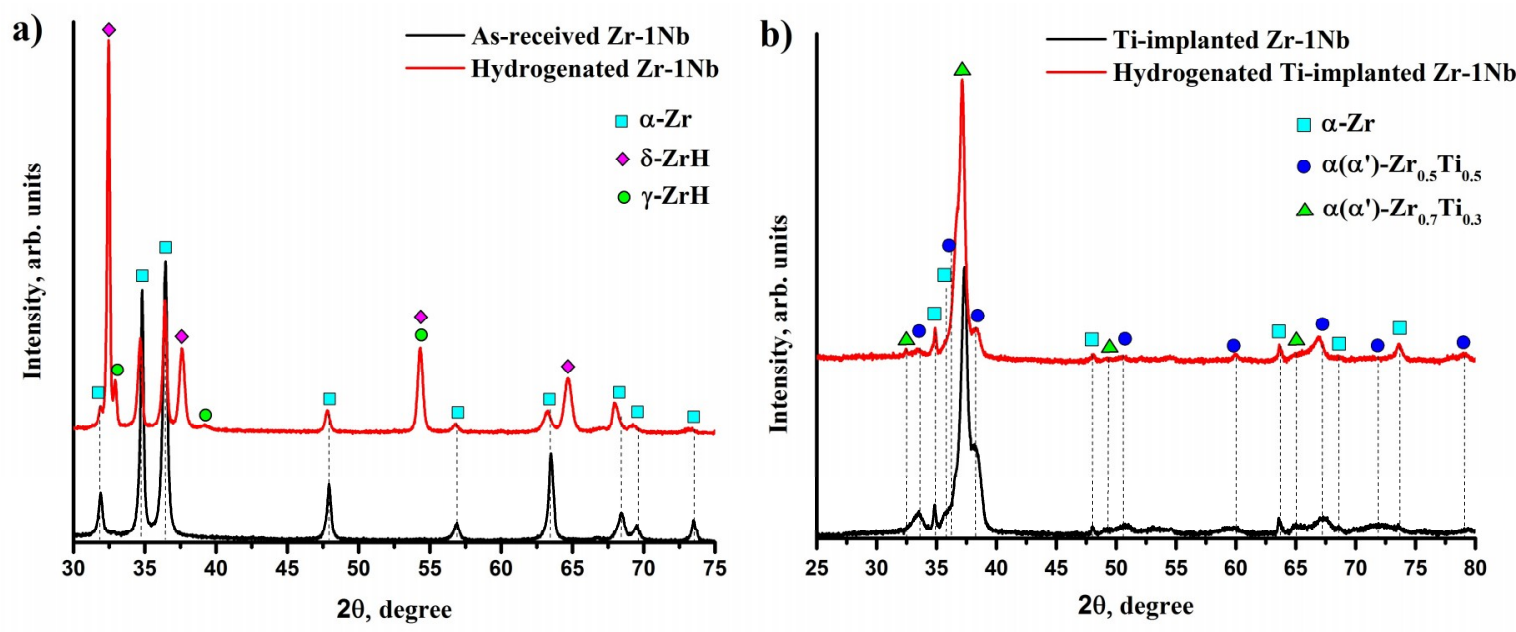

Figure 5. XRD patterns of (a) hydrogenated $\mathrm{Zr}-1 \mathrm{Nb}$ and (b) Ti-implanted $\mathrm{Zr}-1 \mathrm{Nb}$ alloy. 
Such changes could be associated with the formation of hydrides in the surface modified layer. However, there are no pronounced reflexes corresponding to any hydride's phases in the hydrogenated Ti-implanted sample (Figure 5b). Therefore, grazing incidence X-ray diffraction (GIXRD) was used for detailed analysis of the phase composition by the depth of the hydrogenated sample.

Figure 6 shows the XRD patterns recorded at different X-ray incidence angles $(\theta)$. It can be observed that the surface layer is primarily composed of $\alpha^{\prime}-Z_{0.5} \mathrm{Ti}_{0.5}$ phase (Figure 6 at $\theta=5-10$ degrees). In accordance with the results of the depth distribution of hydrogen and measured $\mathrm{H}$ concentration in the sample, we assume that the reflection at the position of $36.25^{\circ}\left(\theta=5^{\circ}\right)$ is attributed to TiZrH hydrides with fcc lattice structure. The intensity of $\alpha^{\prime}-\mathrm{Zr}_{0.5} \mathrm{Ti}_{0.5}$ reflections decreases while the reflection of $\alpha\left(\alpha^{\prime}\right)-\mathrm{Zr}_{0.7} \mathrm{Ti}_{0,3}$ increases with analyzed depth $\left(\theta\right.$ from 5 to $\left.20^{\circ}\right)$. This result indicates that the content of $\alpha\left(\alpha^{\prime}\right)-\mathrm{Zr}_{0.7} \mathrm{Ti}_{0.3}$ is higher in the depth of Ti-implanted layer.

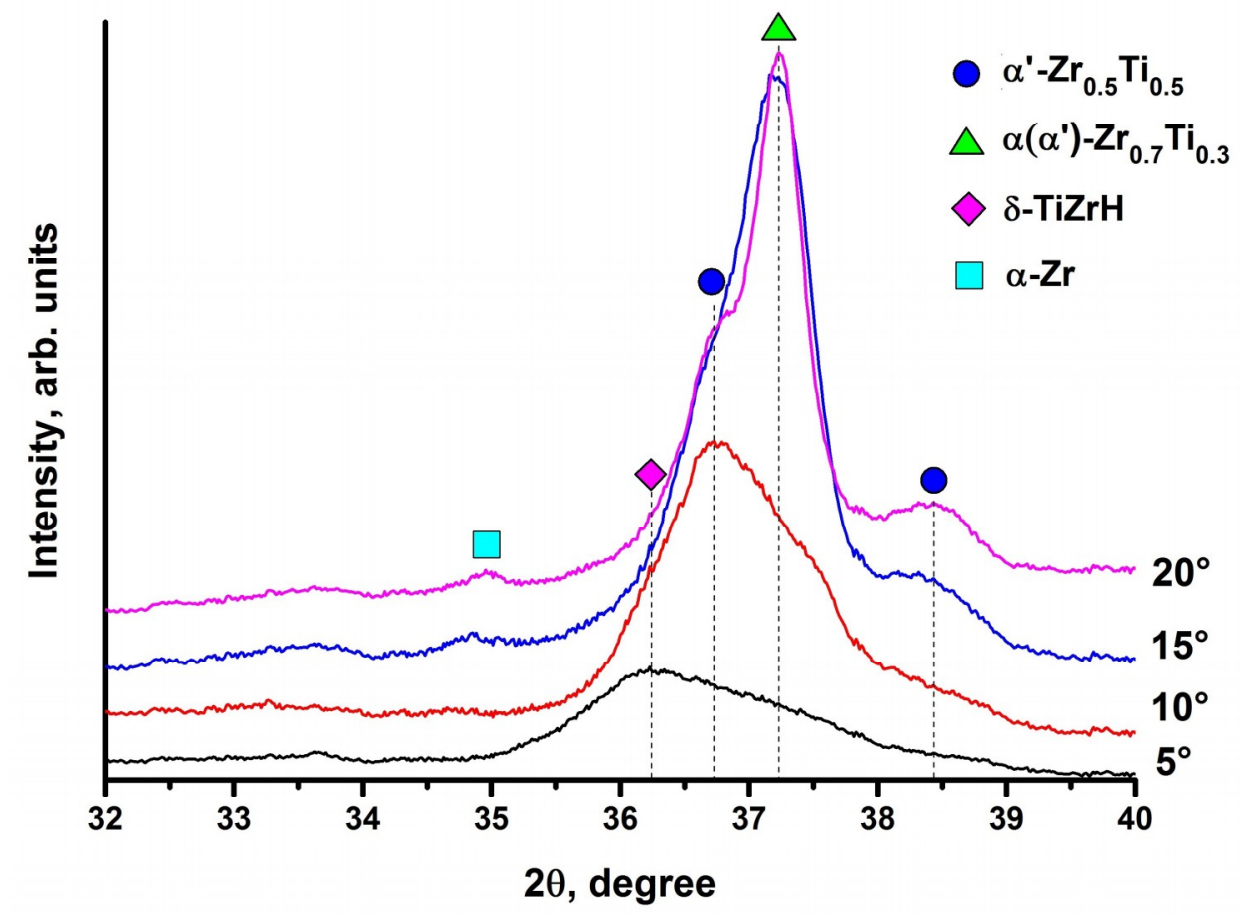

Figure 6. Grazing incidence X-ray diffraction (GIXRD) patterns of the hydrogenated Ti-implanted alloy.

Table 3. Phase composition and lattice parameters of the phases in hydrogenated samples.

\begin{tabular}{|c|c|c|c|c|}
\hline Sample & Phase & Content, vol. $\%$ & Lattice Parameter, Å & $\mathrm{c} / \mathrm{a}$ \\
\hline \multirow{3}{*}{$\mathrm{Zr}-1 \mathrm{Nb}$} & $\alpha-Z r$ (hcp) & 42 & $\begin{array}{l}\mathrm{a}=3.2347 \\
\mathrm{c}=5.1624\end{array}$ & 1.596 \\
\hline & $\delta-\mathrm{ZrH}_{1.66}(\mathrm{fcc})$ & 53 & $\mathrm{a}=4.7654$ & - \\
\hline & $\gamma-\mathrm{ZrH}(\mathrm{fct})$ & 5 & $\begin{array}{l}\mathrm{a}=4.5811 \\
\mathrm{c}=4.9612\end{array}$ & 1.083 \\
\hline \multirow{3}{*}{ Ti-implanted Zr-1Nb } & $\alpha-Z r$ (hcp) & 4 & $\begin{array}{l}a=3.2567 \\
c=5.1508\end{array}$ & 1.582 \\
\hline & $\mathrm{Zr}_{0.5} \mathrm{Ti}_{0.5}$ (hcp) & 50 & $\begin{array}{l}\mathrm{a}=3.0901 \\
\mathrm{c}=4.8931\end{array}$ & 1.583 \\
\hline & $\mathrm{Zr}_{0.7} \mathrm{Ti}_{0.3}(\mathrm{hcp})$ & 46 & $\begin{array}{l}\mathrm{a}=3.1899 ; \\
\mathrm{c}=4.9612\end{array}$ & 1.555 \\
\hline
\end{tabular}


Microstructural analysis was performed on chemically etched samples before and after hydrogenation. The Ti-implanted layer, as mentioned above, consists of a lamellar microstructure with two pronounced layers: the upper layer with typical martensitic microstructure and the lower layer with elongated plates of $\alpha$ (TiZr) phase (Figure 7a). The latter seems to grow inside the primary $\beta$ (TiZr) grains during cooling. Hydrogenation of the Ti-implanted layer has resulted in refinement of the lamellar plates and formation of a more homogeneous microstructure (Figure $7 \mathrm{~b}$ ). The upper layer with the thickness of about 1-2 $\mu \mathrm{m}$ has finer non-lamellar structure, which is probably attributed to the fragmentation of lamellar martensitic plates by TiZr hydrides precipitation.
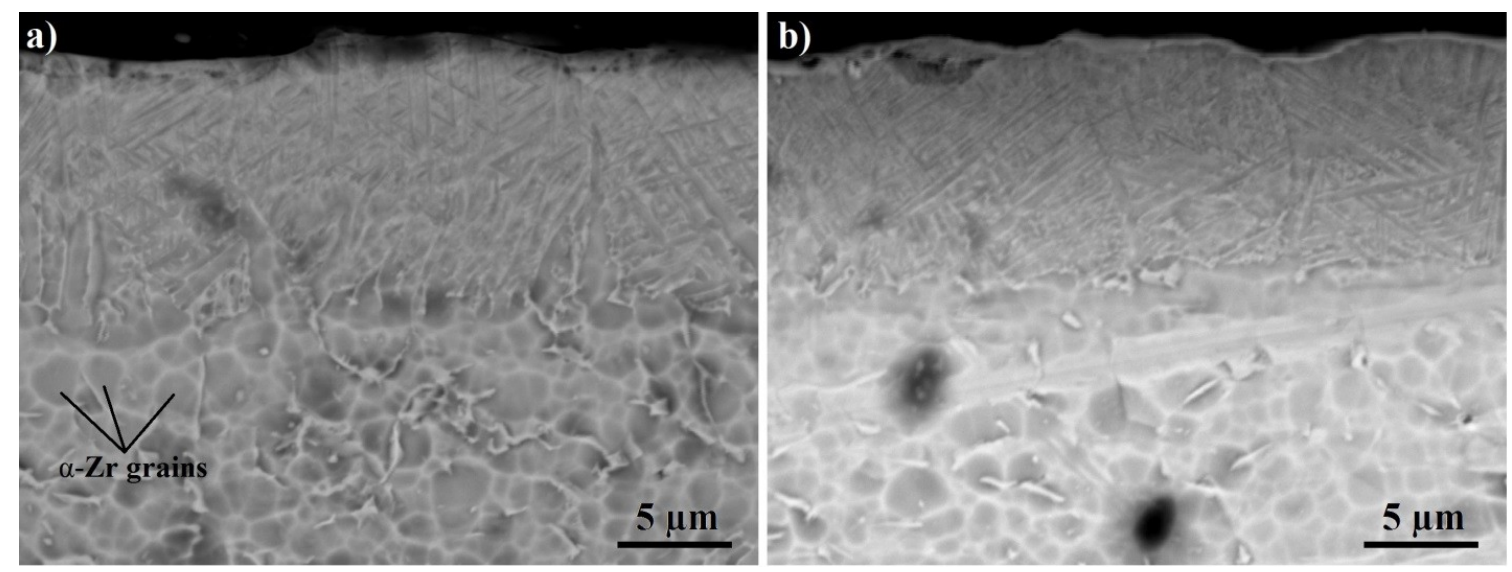

Figure 7. Cross-section SEM images of chemically etched Ti-implanted $\mathrm{Zr}-1 \mathrm{Nb}$ alloy (a) before and (b) after hydrogenation.

\subsection{Thermal Desorption Analysis}

The characteristic of hydrogen desorption from hydrogenated Ti-implanted alloy was evaluated using thermal desorption spectroscopy. Figure 8 shows the TDS spectra of the Ti-implanted $\mathrm{Zr}-1 \mathrm{Nb}$ alloy at the heating rate of $3{ }^{\circ} \mathrm{C} / \mathrm{min}$. It can be observed that hydrogen release starts at approx. $250{ }^{\circ} \mathrm{C}$. Deconvolution of the TDS spectra reveals one low-temperature peak (Peak I) and two high-temperature peaks (Peak II and III). The first peak corresponds to hydrogen desorption from the $\delta(\mathrm{Ti}, \mathrm{Zr}$ ) hydrides followed by $\delta \rightarrow \beta+\delta \rightarrow \beta(\mathrm{Ti}, \mathrm{Zr})$ transformation in the implanted layer occurring at the valley between Peak I and Peak II. There are no published results related to decomposition of TiZrH hydrides, but the similar low-temperature desorption peak at $350-450{ }^{\circ} \mathrm{C}$ has been observed by many authors who studied the desorption of hydrogen from TiH hydrides [43,44]. In addition, in situ X-ray diffraction studies also indicate hydrides decomposition at these temperatures [45,46]. It is believed that the decomposition temperature of TiZrH hydrides is lower than that of $\delta-\mathrm{TiH}$ or $\mathrm{ZrH}$ hydrides due to a reduced $\beta$ transus temperature of TiZr compounds and $\beta$ stabilizing effect of hydrogen. The next hydrogen desorption peak is related to equilibrium hydrogen pressure in the $\beta(\mathrm{Ti}, \mathrm{Zr}$ ) phase of the implanted layer and decomposition of $\delta$ zirconium hydrides in the alloy matrix followed by $\delta \rightarrow \beta+\delta$ $\rightarrow \beta(\mathrm{Zr})$ phase transformations [47]. According to $\mathrm{Zr}-\mathrm{H}$ phase diagram, Peak III is attributed to the equilibrium hydrogen pressure of $\beta(\mathrm{Zr})$ phase, therefore, corresponding to desorption of hydrogen from bcc $\beta(Z r)$ phase of the zirconium alloy.

Thus, after analyzing the data on the hydrogen release, it could be concluded that the formation of TiZr implanted layer provides a lower temperature for hydrogen release and reduces the probability of hydrides formation in the surface layer of the alloy at temperatures of $350{ }^{\circ} \mathrm{C}$ and higher. At the same time, due to the low temperature of $\alpha \rightarrow \beta(\mathrm{Ti}, \mathrm{Zr})$ transformation, the TiZr layer can effectively trap the diffused hydrogen and is less susceptible to hydrogen embrittlement. 


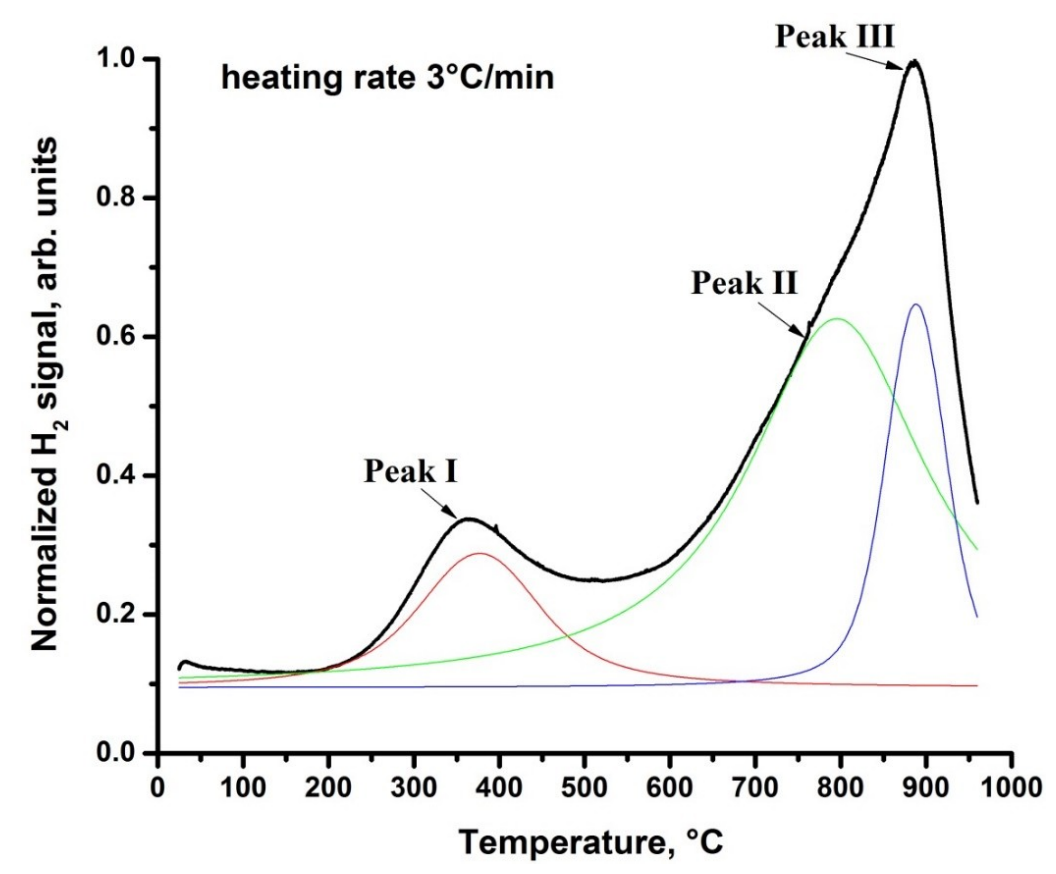

Figure 8. Thermal desorption analysis (TDS) spectra of the hydrogenated Ti-implanted Zr-1Nb alloy.

\section{Conclusions}

High-intensity low energy Ti ion implantation was used for surface modification of $\mathrm{Zr}-1 \mathrm{Nb}$ alloy. The microstructure and phase formation in TiZr surface modified layer, as well as its hydrogen interaction, were studied. Titanium has gradient distribution through the implanted TiZr layer up to $10 \mu \mathrm{m}$ in depth. The modified TiZr layer was represented by $\alpha^{\prime}+\alpha(\mathrm{TiZr})$ lamellar microstructure. The formation of martensite $\alpha^{\prime}$ plates after ion implantation was observed first and was probably related to fast cooling from the $\beta(\mathrm{Ti}, \mathrm{Zr})$ phase after the implantation process. Gas-phase hydrogenation was performed to evaluate the protective properties of the modified layer against hydrogen permeation into $\mathrm{Zr}-1 \mathrm{Nb}$ alloy. It was shown that the formation of TiZr layer provides a significant reduction of hydrogen uptake by zirconium alloy at 400 and $500{ }^{\circ} \mathrm{C}$. Hydrogenation of the modified layer leads to refinement of lamellar plates and formation of a more homogenous microstructure. Thermal desorption spectroscopy revealed lower temperature for hydrogen desorption from TiZr layer. Due to lowering the temperature of $\alpha \rightarrow \beta$ phase transformation by Ti addition, the Ti-modified layer can effectively trap the diffused hydrogen and is less susceptible to hydrogen embrittlement. The obtained results on high-intensity ion implantation and hydrogen interaction with TiZr can be used both to develop functional and protective deep layers on the surface of zirconium alloys, as well as to control the microstructure of the surface modified layer for various applications in industry or medicine

Author Contributions: Conceptualization and methodology, E.B.K. and A.I.R.; Validation, investigation and data curation, A.V.K., M.S.S., A.E.S., A.O. and S.W.; Writing-original draft preparation, E.B.K. and A.I.R.; Supervision, E.B.K.; Project administration and funding acquisition, E.B.K. and M.S.S.

Funding: The reported research was funded by the Russian Foundation for Basic Research and the government of the Tomsk region of the Russian Federation, grant No. 18-48-703034. The TDS analysis was funded by the Governmental program "Science", research project No. 11.3683.2017/4.6.

Acknowledgments: The research was carried out within the framework of Tomsk Polytechnic University Competitiveness Enhancement Program.

Conflicts of Interest: The authors declare no conflict of interest. 


\section{References}

1. Sarkar, A.; Chandanshive, S.A.; Thota, M.K.; Kapoor, R. High temperature deformation behavior of Zr- $1 \mathrm{Nb}$ alloy. J. Alloys Compd. 2017, 703, 56-66. [CrossRef]

2. Lee, C.M.; Mok, Y.-K.; Sohn, D.-S. High-temperature steam oxidation and oxide crack effects of Zr-1Nb-1Sn-0.1Fe fuel cladding. J. Nucl. Mater. 2017, 496, 343-352. [CrossRef]

3. Ensor, B.; Lucente, A.M.; Frederick, M.J.; Sutliff, J.; Motta, A.T. The role of hydrogen in zirconium alloy corrosion. J. Nucl. Mater. 2017, 496, 301-312. [CrossRef]

4. Kishore, R. Effect of hydrogen on the creep behavior of Zr-2.5\%Nb alloy at 723 K. J. Nucl. Mater. 2009, 385, 591-594. [CrossRef]

5. Wei, T.; Long, C.; Chen, H. Hydrogen uptake behaviors of Zr-1.0Cr-0.4Fe-(0.2Mo) and N18 alloys during corrosion in $500{ }^{\circ} \mathrm{C}$ steam. J. Alloys Compd. 2018, 731, 126-134. [CrossRef]

6. Couet, A.; Motta, A.T.; Comstock, R.J. Hydrogen pickup measurements in zirconium alloys: Relation to oxidation kinetics. J. Nucl. Mater. 2014, 451, 1-13. [CrossRef]

7. Tagtstrom, P.; Limback, M.; Dahlback, M.; Andersson, T.; Pettersson, H. Effects of Hydrogen Pickup and Second- Phase Particle Dissolution on the In-Reactor Corrosion Performance of BWR Claddings. In Zirconium in the Nuclear Industry: 13th International Symposium, ASTM STP 1423; ASTM International: West Conshohocken, PA, USA, 2002; pp. 96-118.

8. Krishna, K.M.; Srivastava, D.; Dey, G.K.; Hiwarkar, V.; Samajdar, I.; Banerjee, S. Role of grain/phase boundary nature on the formation of hydrides in $\mathrm{Zr}-2.5 \% \mathrm{Nb}$ alloy. J. Nucl. Mater. 2011, 414, 270-275. [CrossRef]

9. Bair, J.; Asle Zaeem, M.; Tonks, M. A review on hydride precipitation in zirconium alloys. J. Nucl. Mater. 2015, 466, 12-20. [CrossRef]

10. McRae, G.A.; Coleman, C.E.; Leitch, B.W. The first step for delayed hydride cracking in zirconium alloys. J. Nucl. Mater. 2010, 396, 130-143. [CrossRef]

11. Große, M.; Lehmann, E.; Steinbrück, M.; Kühne, G.; Stuckert, J. Influence of oxide layer morphology on hydrogen concentration in tin and niobium containing zirconium alloys after high temperature steam oxidation. J. Nucl. Mater. 2009, 385, 339-345. [CrossRef]

12. Terrani, K.A. Accident tolerant fuel cladding development: Promise, status, and challenges. J. Nucl. Mater. 2018, 501, 13-30. [CrossRef]

13. Cox, B. Some thoughts on the mechanisms of in-reactor corrosion of zirconium alloys. J. Nucl. Mater. 2005, 336, 331-368. [CrossRef]

14. Duan, Z.; Yang, H.; Satoh, Y.; Murakami, K.; Kano, S.; Zhao, Z.; Shen, J.; Abe, H. Current status of materials development of nuclear fuel cladding tubes for light water reactors. Nucl. Eng. Des. 2017, 316, 131-150. [CrossRef]

15. Kuprin, A.S.; Belous, V.A.; Voyevodin, V.N.; Vasilenko, R.L.; Ovcharenko, V.D.; Tolstolutskaya, G.D.; Kopanets, I.E.; Kolodiy, I.V. Irradiation resistance of vacuum arc chromium coatings for zirconium alloy fuel claddings. J. Nucl. Mater. 2018, 510, 163-167. [CrossRef]

16. Bischoff, J.; Delafoy, C.; Vauglin, C.; Barberis, P.; Roubeyrie, C.; Perche, D.; Duthoo, D.; Schuster, F.; Brachet, J.-C.; Schweitzer, E.W.; et al. AREVA NP's enhanced accident-tolerant fuel developments: Focus on Cr-coated M5 cladding. Nucl. Eng. Technol. 2018, 50, 223-228. [CrossRef]

17. Alat, E.; Motta, A.T.; Comstock, R.J.; Partezana, J.M.; Wolfe, D.E. Multilayer (TiN, TiAlN) ceramic coatings for nuclear fuel cladding. J. Nucl. Mater. 2016, 478, 236-244. [CrossRef]

18. Kim, I.; Khatkhatay, F.; Jiao, L.; Swadener, G.; Cole, J.I.; Gan, J.; Wang, H. TiN-based coatings on fuel cladding tubes for advanced nuclear reactors. J. Nucl. Mater. 2012, 429, 143-148. [CrossRef]

19. Khatkhatay, F.; Jiao, L.; Jian, J.; Zhang, W.; Jiao, Z.; Gan, J.; Zhang, H.; Zhang, X.; Wang, H. Superior corrosion resistance properties of TiN-based coatings on Zircaloy tubes in supercritical water. J. Nucl. Mater. 2014, 451, 346-351. [CrossRef]

20. Zou, Z.; Xue, W.; Jia, X.; Du, J.; Wang, R.; Weng, L. Effect of voltage on properties of microarc oxidation films prepared in phosphate electrolyte on Zr-1Nb alloy. Surf. Coat. Technol. 2013, 222, 62-67. [CrossRef]

21. Van Nieuwenhove, R.; Andersson, V.; Balak, J.; Oberländer, B. In-Pile Testing of CrN, TiAlN, and AlCrN Coatings on Zircaloy Cladding in the Halden Reactor. In Zirconium in the Nuclear Industry: 18th International Symposium; ASTM International: West Conshohocken, PA, USA, 2018; pp. 965-982. 
22. Pushilina, N.S.; Kudiiarov, V.N.; Lider, A.M.; Teresov, A.D. Influence of surface structure on hydrogen interaction with Zr-1Nb alloy. J. Alloys Compd. 2015, 645, S476-S479. [CrossRef]

23. Kashkarov, E.; Nikitenkov, N.; Sutygina, A.; Laptev, R.; Bordulev, Y.; Obrosov, A.; Liedke, M.O.; Wagner, A.; Zak, A.; Wei $\beta$, S. Microstructure, defect structure and hydrogen trapping in zirconium alloy $\mathrm{Zr}-1 \mathrm{Nb}$ treated by plasma immersion Ti ion implantation and deposition. J. Alloys Compd. 2018, 732, 80-87. [CrossRef]

24. Kashkarov, E.B.; Nikitenkov, N.N.; Sutygina, A.N.; Obrosov, A.; Manakhov, A.; Polčák, J.; Weiß, S. Hydrogen absorption by Ti-implanted Zr-1Nb alloy. Int. J. Hydrog. Energy 2018, 43, 2484-2491. [CrossRef]

25. Peng, D.Q.; Bai, X.D.; Pan, F.; Sun, H.; Chen, B.S. Influence of titanium ions implantation on corrosion behavior of zirconium in $1 \mathrm{M} \mathrm{H}_{2} \mathrm{SO}_{4}$. Appl. Surf. Sci. 2006, 252, 2196-2203. [CrossRef]

26. Obrosov, A.; Sutygina, A.; Manakhov, A.; Bolz, S.; Weiß, S.; Kashkarov, E. Oxidation Behavior of Zr-1Nb Corroded in Air at $400{ }^{\circ} \mathrm{C}$ after Plasma Immersion Titanium Implantation. Metals 2018, 8, 27. [CrossRef]

27. Ryabchikov, A.I.; Kashkarov, E.B.; Pushilina, N.S.; Syrtanov, M.S.; Shevelev, A.E.; Korneva, O.S.; Sutygina, A.N.; Lider, A.M. High-intensity low energy titanium ion implantation into zirconium alloy. Appl. Surf. Sci. 2018, 439, 106-112. [CrossRef]

28. Al-Nawas, B.; Brägger, U.; Meijer, H.J.A.; Naert, I.; Persson, R.; Perucchi, A.; Quirynen, M.; Raghoebar, G.M.; Reichert, T.E.; Romeo, E.; et al. A Double-Blind Randomized Controlled Trial (RCT) of Titanium-13Zirconium versus Titanium Grade IV Small-Diameter Bone Level Implants in Edentulous Mandibles—Results from a 1-Year Observation Period. Clin. Implant Dent. Relat. Res. 2012, 14, 896-904. [CrossRef] [PubMed]

29. Ferreira, E.A.; Rocha-Filho, R.C.; Biaggio, S.R.; Bocchi, N. Corrosion resistance of the Ti-50Zr at.\% alloy after anodization in different acidic electrolytes. Corros. Sci. 2010, 52, 4058-4063. [CrossRef]

30. Li, Y.; Cui, Y.; Zhang, F.; Xu, H. Shape memory behavior in Ti-Zr alloys. Scr. Mater. 2011, 64, 584-587. [CrossRef]

31. Frank, M.J.; Walter, M.S.; Lyngstadaas, S.P.; Wintermantel, E.; Haugen, H.J. Hydrogen content in titanium and a titanium-zirconium alloy after acid etching. Mater. Sci. Eng. C 2013, 33, 1282-1288. [CrossRef]

32. Ryabchikov, A.I.; Ananin, P.S.; Dektyarev, S.V.; Sivin, D.O.; Shevelev, A.E. High intensity metal ion beam generation. Vacuum 2017, 143, 447-453. [CrossRef]

33. Stout, V.L.; Gibbons, M.D. Gettering of gas by titanium. J. Appl. Phys. 1955, 26, 1488-1492. [CrossRef]

34. Anders, A. (Ed.) Handbook of Plasma Immersion Ion Implantation and Deposition; Wiley: New York, NY, USA, 2000; Volume 17, p. 46.

35. Yushkov, G.Y.; Anders, A.; Oks, E.M.; Brown, I.G. Ion velocities in vacuum arc plasmas. J. Appl. Phys. 2000, 88,5618-5622. [CrossRef]

36. Ryabchikov, A.I.; Sivin, D.O.; Korneva, O.S.; Lopatin, I.V.; Ananin, P.S.; Prokopenko, N.A.; Akhmadeev, Y.K. High-current-density gas ion ribbon beam formation. Nucl. Instrum. Methods Phys. Res. Sect. A Accel. Spectrom. Detect. Assoc. Equip. 2018, 906, 56-60. [CrossRef]

37. Richmond, C.J. Ion Implantation; Ryssel, H., Ruge, I., Eds.; Wiley: Chichester, UK, 1986; 478p.

38. Babikhina, M.N.; Kudiiarov, V.N.; Mostovshchikov, A.V.; Lider, A.M. Quantitative and Qualitative Analysis of Hydrogen Accumulation in Hydrogen-Storage Materials Using Hydrogen Extraction in an Inert Atmosphere. Metals 2018, 8, 672. [CrossRef]

39. Dobromyslov, A.V.; Taluts, N.I. Structure investigation of quenched and tempered alloys of the $\mathrm{Zr}-\mathrm{Ti}$ system. Phys. Met. Met. 1987, 63, 114-120.

40. Zhou, Y.K.; Jing, R.; Ma, M.Z.; Liu, R.P. Tensile strength of Zr-Ti binary alloy. Chin. Phys. Lett. 2013, 30, 116201. [CrossRef]

41. Liang, S.X.; Yin, L.X.; Zhou, Y.K.; Feng, X.J.; Ma, M.Z.; Liu, R.P.; Tan, C.L. Abnormal martensitic transformation of high Zr-containing Ti alloys. J. Alloys Compd. 2014, 615, 804-808. [CrossRef]

42. Lin, C.; Yin, G.; Zhao, Y.; Ge, P.; Liu, Z. Analysis of the effect of alloy elements on martensitic transformation in titanium alloy with the use of valence electron structure parameters. Mater. Chem. Phys. 2011, 125, 411-417. [CrossRef]

43. Ma, M.; Liang, L.; Wang, L.; Wang, Y.; Cheng, Y.; Tang, B.; Xiang, W.; Tan, X. Phase transformations of titanium hydride in thermal desorption process with different heating rates. Int. J. Hydrog. Energy 2015, 40, 8926-8934. [CrossRef]

44. Suwarno, S.; Yartys, V.A. Kinetics of hydrogen absorption and desorption in titanium. Bull. Chem. React. Eng. Catal. 2017, 12, 312-317. [CrossRef] 
45. Laptev, R.S.; Syrtanov, M.S.; Kudiiarov, V.N.; Shmakov, A.N.; Vinokurov, Z.S.; Mikhaylov, A.A.; Zolotarev, K.V. In Situ Investigation of Thermo-stimulated Decay of Hydrides of Titanium and Zirconium by Means of X-ray Diffraction of Synchrotron Radiation. In Physics Procedia; Elsevier: Amsterdam, The Netherlands, 2016; Volume 84, pp. 337-341.

46. Jiménez, C.; Garcia-Moreno, F.; Pfretzschner, B.; Klaus, M.; Wollgarten, M.; Zizak, I.; Schumacher, G.; Tovar, M.; Banhart, J. Decomposition of TiH2studied in situ by synchrotron X-ray and neutron diffraction. Acta Mater. 2011, 59, 6318-6330. [CrossRef]

47. Ma, M.; Liang, L.; Tang, B.; Xiang, W.; Wang, Y.; Cheng, Y.; Tan, X. Decomposition kinetics study of zirconium hydride by interrupted thermal desorption spectroscopy. J. Alloys Compd. 2015, 645, S217-S220. [CrossRef]

2018 by the authors. Licensee MDPI, Basel, Switzerland. This article is an open access article distributed under the terms and conditions of the Creative Commons Attribution (CC BY) license (http://creativecommons.org/licenses/by/4.0/). 